\title{
Increasing Integration Across the Supply Chain Through an Approach to Match Performance and Risk
}

\author{
${ }^{1}$ Maria Elena Nenni and ${ }^{2}$ Luca Giustiniano \\ ${ }^{1}$ Department of Industrial Engineering, University of Naples "Federico II", Naples, Italy \\ ${ }^{2}$ Department of Business and Management, University LUISS Guido Carli, Rome, Italy
}

Received 2013-07-22, Revised 2013-07-29; Accepted 2013-07-30

\begin{abstract}
It is well known by researchers and practitioners that shared risks among actors support integration and collaboration across a supply chain. Moreover many authors have linked risk to performance contribution. Nevertheless these ideas remain still theoretical and in literature applications are missing. The aim of this study is to develop a logical framework in which risk, performance and actors are connected each other. The goal is using the framework as a tool to recognize unbalanced supply chains and the best way to improve them. The benefit should be a better integration among supply chain actors. The logical framework has been thought and then applied in the case of an Integrated Logistic Support (ILS) service.
\end{abstract}

Keywords: Integration, Risk, Performance, Supply Chain, Logistic Support

\section{INTRODUCTION}

Despite the attention that both practitioners and academics have paid in the last decades to the Supply Chain Management (SCM), many aspects still remain unexplored. Firstly the emphasis in SCM is strongly skewed toward the manufacturing sector (Boon-itt and Pongpanarat, 2011). Then the most considerable efforts have been expended to investigate operational areas of SCM. Moreover many decision support systems even stimulating cooperation and effective relationship management. According to Narasimhan and Schoenherr (2012), this is mainly due to a specific focus, generally facility location or buyer-supplier relationship, rather than a global perspective.

In this study our aim is to propose an approach to increase integration and cooperation across a global supply chain. The main idea is that integration should be incentivized through a well- balanced risk among supply chain actors. This clue has been supported since by Miller (1992), who has firstly recognized a positive link between shared risk and cooperation, among developed at strategic as well as tactical level, fail in

supply chain actors. Other authors (Ritchie et al., 2008; Oehmen et al., 2009) have then interrelated the risk to the performance and it represents the base of our conceptual framework in which risk is correctly shared using performance metrics as drivers.

Our approach starts from charting a model for the supply chain in order to pick out the best-fitting performance evaluation system (Estampe et al., 2013). The proposal is then structured to develop the conceptual framework in which we firstly find a match between performance metrics and actors and risk consequences and actors. Finally we evaluate virtual paths linking performance and risk and passing through actors. Number, consistency and completeness of paths are indicators to find out unbalanced risk or an exposure to risk that is unsustainable for actors.

We have applied our approach to a global supply chain in the after sale services industry. The specific application concerns the Integrated Logistic Support (ILS) services. The case has the aim to get off a too generic approach. Moreover we have chosen to deal with this specific supply chain in the after-sales services Corresponding Author: Maria Elena Nenni, Department of Industrial Engineering, University of Naples "Federico II", Naples, Italy 
because it has distinctive features that increase the complexity and make it a good test-bed.

The study is structured as follows: Section 2 is devoted to analyze the context of an ILS service. Section 3 introduces the conceptual framework from the supply chain modeling to the way of building a link between risk and performance. In Section 4 the application is presented and results discussed. Finally section 5 summarizes the findings and provides some final remarks.

\subsection{Analysis of the Context}

In order to develop the conceptual framework, we have to analyze some features of the context of ILS. The approach proposed in this study aims at being generalized, but not completely theoretical. So we have had the case in mind since the first stage of the research.

Integrated Logistics Support (ILS) is an integrated approach to the management of logistic disciplines in the military, similar to commercial product support or customer service organizations (Army Regulation 700127, 2012). Although originally developed for military purposes, it is applied by the private sector as well. In general, ILS plans and directs the identification and development of logistics support and system requirements for military systems, with the goal of creating systems that last longer and require less support, thereby reducing costs and increasing return on investments. ILS therefore, addresses these aspects of supportability not only during acquisition, but also throughout the operational life cycle of the system. The impact of ILS is often measured in terms of metrics such as Reliability, Availability, Maintainability and Testability (RAMT) and sometimes System Safety (RAMS). The ILS Supply Chain (ILS-SC) has usually few actors. The main ones are the Spare Parts Providers (SPP), a Contractor Logistic Support (CLS) and the customer. The relationship among them is really complex, because they have different background (the customer is the only one coming from military industry) and operate in a very different way. The CLS affects the maintenance tasks on the customer system and becomes responsible for system availability. He relies on a network of SPPs that are in partnership with him. The fee for Logistic Support services is completely linked to the system availability. However it doesn't seem a very effective way. Mainly, this doesn't take into consideration the influence of customer on the system availability. Then an opportunistic behavior could be generated by the CLS, who could choose a trade off between cost for the service and cost of service level, instead of pursuing the best availability for the customer. Lastly, each actor shifts his own risk on the upstream partner. Our aim is to attribute rightly the weight of each actor on the final performance. It should bring to individuate more correctly the fees and to a risk efficiently shared.

\subsection{The Conceptual Framework}

By the analysis of the ILS context we have been inspired to develop a framework of the study. The approach can be divided into five main stages:

- Modeling the supply chain: it aims at individuate main features of the supply chain as actors, servitization rate, level of globalization, configuration choices and maturity level

- Choosing the evaluation model: Because the profusion of performance evaluation models in literature, we have to operate a choice using features of previous stage

- Attributing the performance to the actor: it breakdowns the performance dimensions into metrics and then into drivers, that can be more easily attributed to actors

- Managing the supply chain risk: as in the previous stage, we have used the general risk management approach (PMI, 2013) to arrive at risk consequences that affect each SC actor.

- Linking risk to the performance evaluation: it aims at individuating links between risk and performance and at analyzing them in order to understand if the supply chain is unbalanced from a point of view of risk

\subsection{Modeling the Supply Chain}

We are considering a specific kind of after-sales service in which we have three types of main actors: SPPs, CLS and customer (with multiple location). SPPs and CLS belong to the civilian industry while the customer belongs to the military one.

The SC is a mixed product-service SC, in which the SPP provides spare parts and the CLS provides a maintenance service (servitized product).

According to Saccani et al. (2007) the SC model depends on three specific configuration choices: (i) the degree of vertical integration of after- sales activities by the finished goods manufacturer, (ii) the degree of centralization of the resources and actors that carry out the activities and (iii) the decoupling of activities between and within different organizations.

Referring to the degree of vertical integration in an ILS-SC the finished goods manufacturer completely overlaps the CLS who performs the after sales activities. 
On the other hand the CLS is usually completely independent from the SPPs.

As pointed out by Zhen (2011), one common kind of centralization is that of inventories and warehousing. ILS$\mathrm{SC}$ can be viewed even as a Hub\&Spoke model because the spare part is held at the SPP. It is then sent out to the Customer only when it is needed.

A common way to decouple in service organizations is by separating the activities that require customer interaction (front office) from the ones that do not (back office), enhance specialization in order to increase efficiency as well as to reduce delivery lead time (Singh, 2009). Front office activities are under the influence of the only CLS, while back office one are divided between CLS and SPPs who, according to Broekhuis et al. (2009) apply a centralization policy. Especially for services, proximity to customers is a critical aspect, as the customer is often participating in service production. However it is completely left to the CLS.

Another way to analyze the SC, really useful for our objective, is through the maturity level: the maturity classification proposed in the Supply Chain Operations Reference (SCOR) model relates to companies' ability to manage a full scope of a supply chain (Zhou et al., 2011).

In the ILS-SC the aim should be to go from Level 2 to Level 3 as described in the Table 1.

According to Pache and Spalanzani (2007) at Level 3 corresponds extended inter-organizational maturity, with all of the actors in a chain being involved in the search for better performance (i) very regular exchanges with partners, (ii) contracts and partnership agreements signed with all actors, (iii) overall vision of value creation and, above all, (iv) risks and profits shared.

\subsection{Choosing the Evaluation Model}

In order to link risk and performance each other, we have to individuate a specific evaluation model. We have used features of the SC model to guide the choice.

We have taken into consideration the study of Estampe et al. (2013) and, on the base of the SC model as in the previous section, we have selected two possible evaluation models. According to the authors we have used as drivers for the choice: (i) decision level (tactical), (ii) type of flows (physical and informational) and (iii) level of maturity (Level 2). Two models for evaluating the performance are possible:

- SC Operations reference model (SCOR): the SC Council has developed it in 1996. It aims to analyze 5 dimensions: Reliability (R), Flexibility (F), Responsiveness (Re), Costs (C) and Asset
Management (AM). R, F and Re concern all the customer satisfaction. The other factors are instead connected to the actors' capability

- SCALE: SC Advisor Level of Evaluation: it ahs been created at early 2000 s by the Institute for SC Excellence. It revolves around a questionnaire that investigates the value creation elements

Between SCOR and SCALE, we have decided to adopt the SCOR model because questionnaire is not sustainable in our case. Moreover SCALE model doesn't consider quality factors, as injection of quality approach into the logistic vision; but in the context of ILS-SC elements such as continuous improvement and customer satisfaction are really relevant. Clearly the choice of the evaluation model is not a general issue but it is essentially connected to the case. That is the reason for which the study starts creating the supply chain model.

\subsection{Attributing the Performance to the Actors}

Through opportune metrics it is possible to attribute the contribution of each actor on the performance. We can do it surely in a qualitative way as well as calculating a percentage of contribution of each actor on the metrics. The way to a sure attribution is to breakdown the metrics structure in order to create a unique match from a metric to an actor as in the Fig. 1.

\subsection{Managing the Supply Chain Risk}

Many authors (Ritchie et al., 2008; Oehmen et al., 2009) say that creating a shareholder value requires an integrated approach to performance and risk management. According to Wagner and Bode (2008) it is possible to define supply chain risk as the negative deviation from the expected value of a certain performance measure. Waters (2011) define 'risk' as "the variation in the distribution of possible supply chain outcomes, their likelihood and their subjective values".

Juttner et al. (2003) suggests that supply chain relevant risk sources fall into three categories:

- Environmental risk sources (E): They comprise any uncertainties arising from the supply chain environment interaction. These may be the result of accidents (e.g., fire), socio-political actions (e.g., fuel protests or terrorist attacks) or acts of God (e.g., extreme weather or earthquakes)

- Organizational risk sources (O): They lie within the boundaries of the supply chain parties and range from labor (e.g., strikes) or production uncertainties (e.g., machine failure) to IT-system uncertainties 
Table 1. From Level 2 to Level 3 of maturity (SCOR)

\begin{tabular}{lll}
\hline Description & Goal & \\
\hline Level 2 & Internal integration & $\begin{array}{l}\text { To devise tools to measure transversal } \\
\text { performance within the company, thereby } \\
\text { validating overall performance by seeking an } \\
\text { optimum between the demand for resources. } \\
\text { To extend performance measurement for shared } \\
\text { to the company's key external actors, } \\
\text { while associating them with the search performance. }\end{array}$ \\
\hline
\end{tabular}

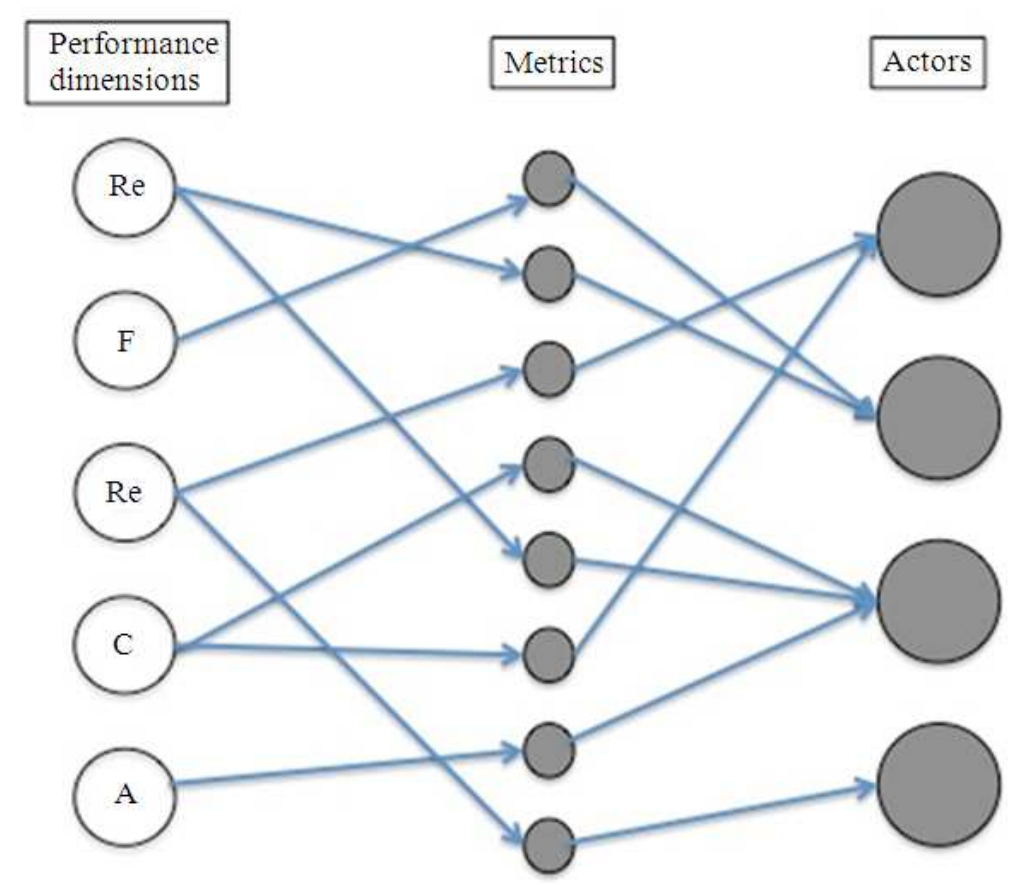

Fig. 1. Through a metric breakdown structure the attribution of performance to actors is made

- $\quad$ Network-related risk sources $(\mathrm{N})$ : They arise from interactions between organizations within the supply chain. Whatever damage is caused by suboptimal interaction between the organizations along the chain is attributable to network-related risk sources. In this sense, environmental and organizational uncertainties are risk sources 'to' the various links in the supply chain and networkrelated uncertainties are risk sources 'of' the various links (Teng and Das, 2008)

Through the same procedure of previous section, risk sources can be analyzed by consequences that should be detailed enough to be linked to the actors (Fig. 2). The problem should be the quantitative approach through which we want to assign a risk factor to each actor because too detailed risk consequences should be correlated each other.

\subsection{Linking Risk to the Performance Evaluation}

Joining results from stages 3 and 4 , we can create a logical link between risk, performance and actors (Fig. 3).

Going through the framework is an effective way to understand critical paths in the supply chain, in which risk factors and performances are ascribable to a specific actor. We define the framework as unbalanced if one of the three following cases happens:

- The most part of risks impacts on one or few actors (Fig. 4)

- The most part of performance contribution comes from one or few actors (Fig. 5) 
- Actors who are exposed to risk don't contribute to the performance. The evidence is that paths in the framework are interrupted (Fig. 6)

A general result of the proposed framework is an advance on the Ritchie et al. (2008). They recognize a link between risk sources and performance dimension, but they do not mention particular drivers because in their opinion a generalization is practically impossible.

Through the proposed framework, it is possible to establish the link at any rate in the specific context. If the framework results well-balanced, the paths can be used as reference for any project or activity in the supply chain.

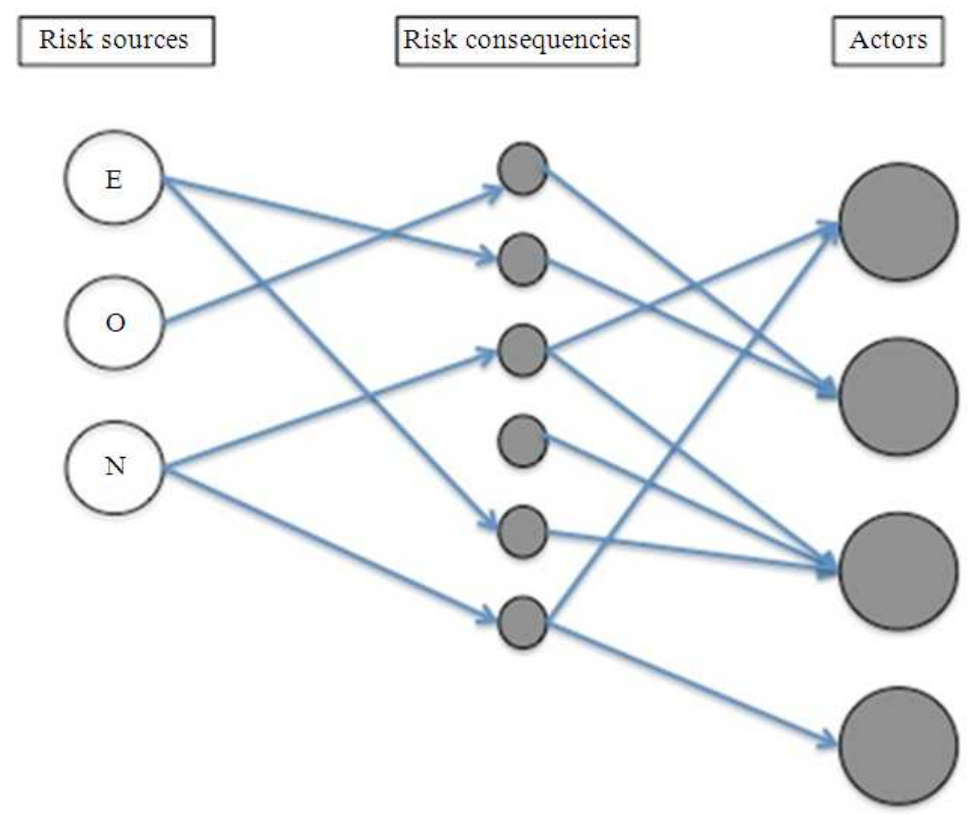

Fig. 2. Through a risk breakdown structure the link between risk and actors is made

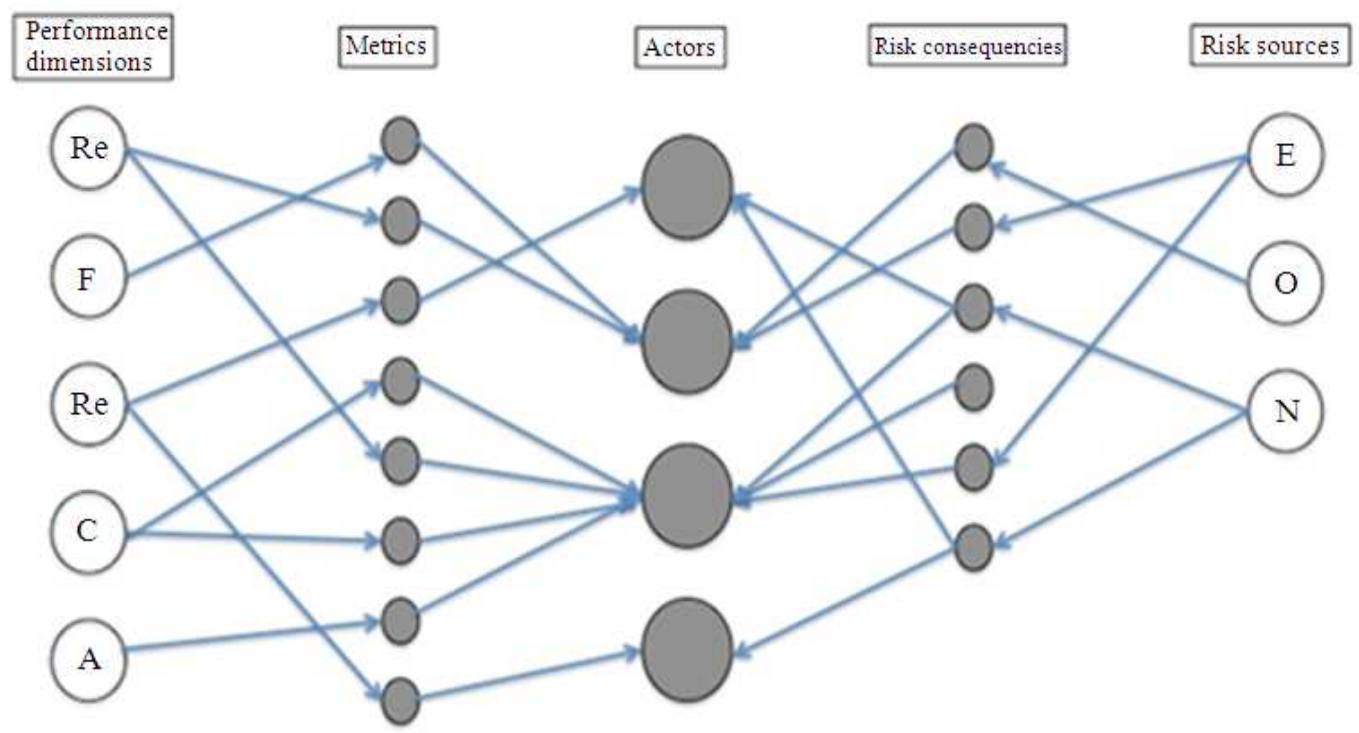

Fig. 3. Framework to link risk to the performance evaluation 
Maria Elena Nenni and Luca Giustiniano / American Journal of Applied Sciences 10 (9): 1009-1017, 2013

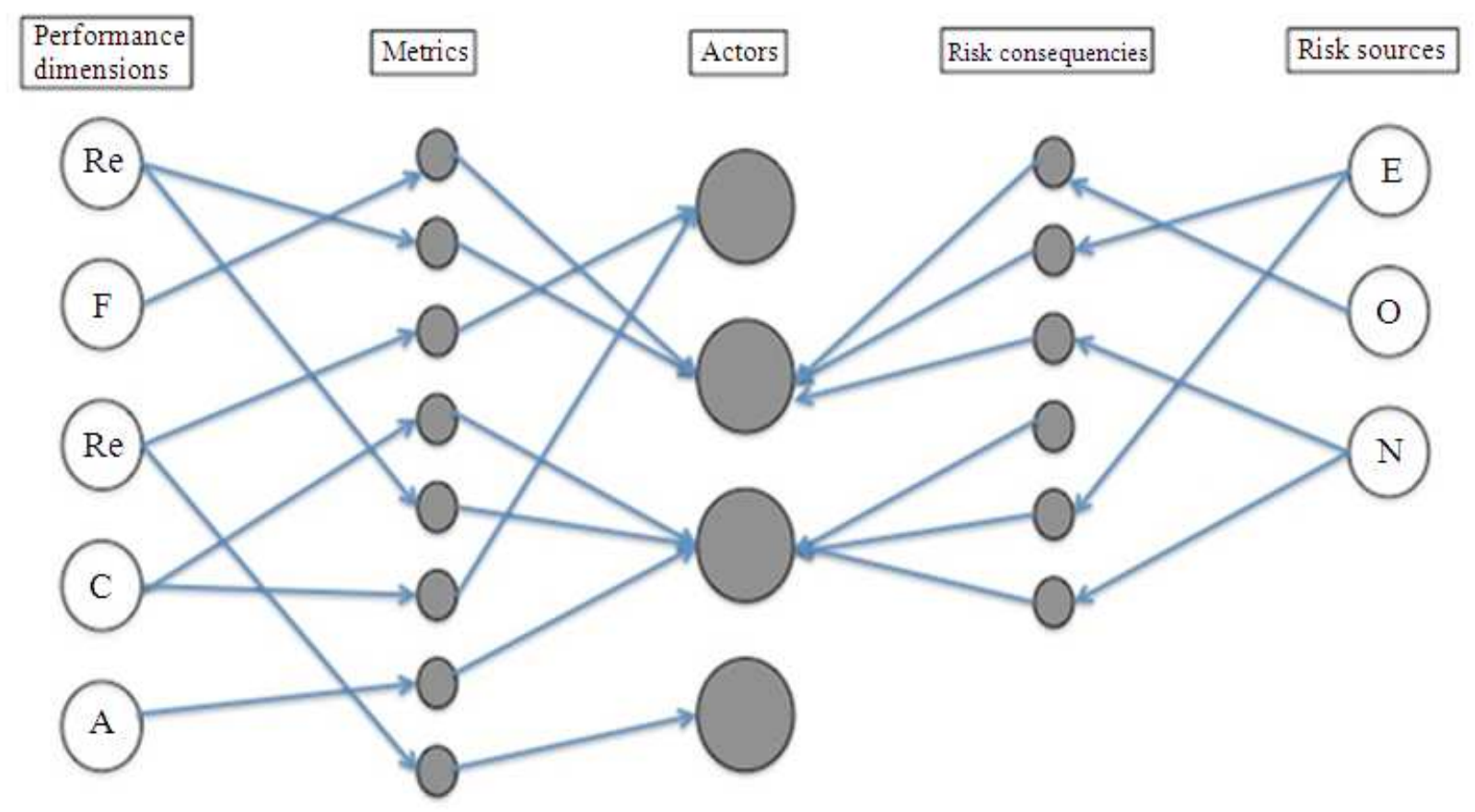

Fig. 4. The most part of risk impacts on few actors

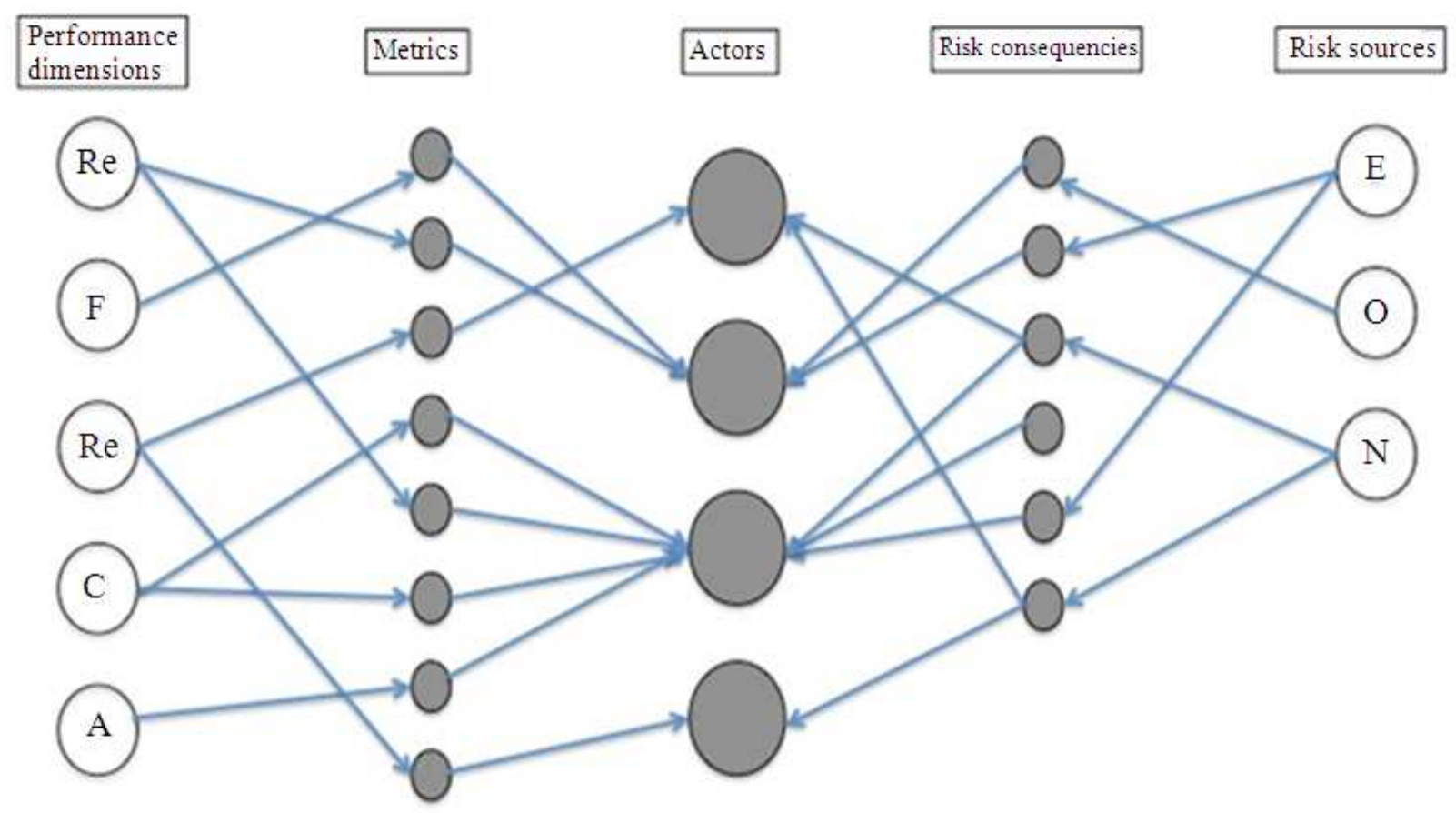

Fig. 5. The most part of performance contribution comes from one or few actors 
Maria Elena Nenni and Luca Giustiniano / American Journal of Applied Sciences 10 (9): 1009-1017, 2013

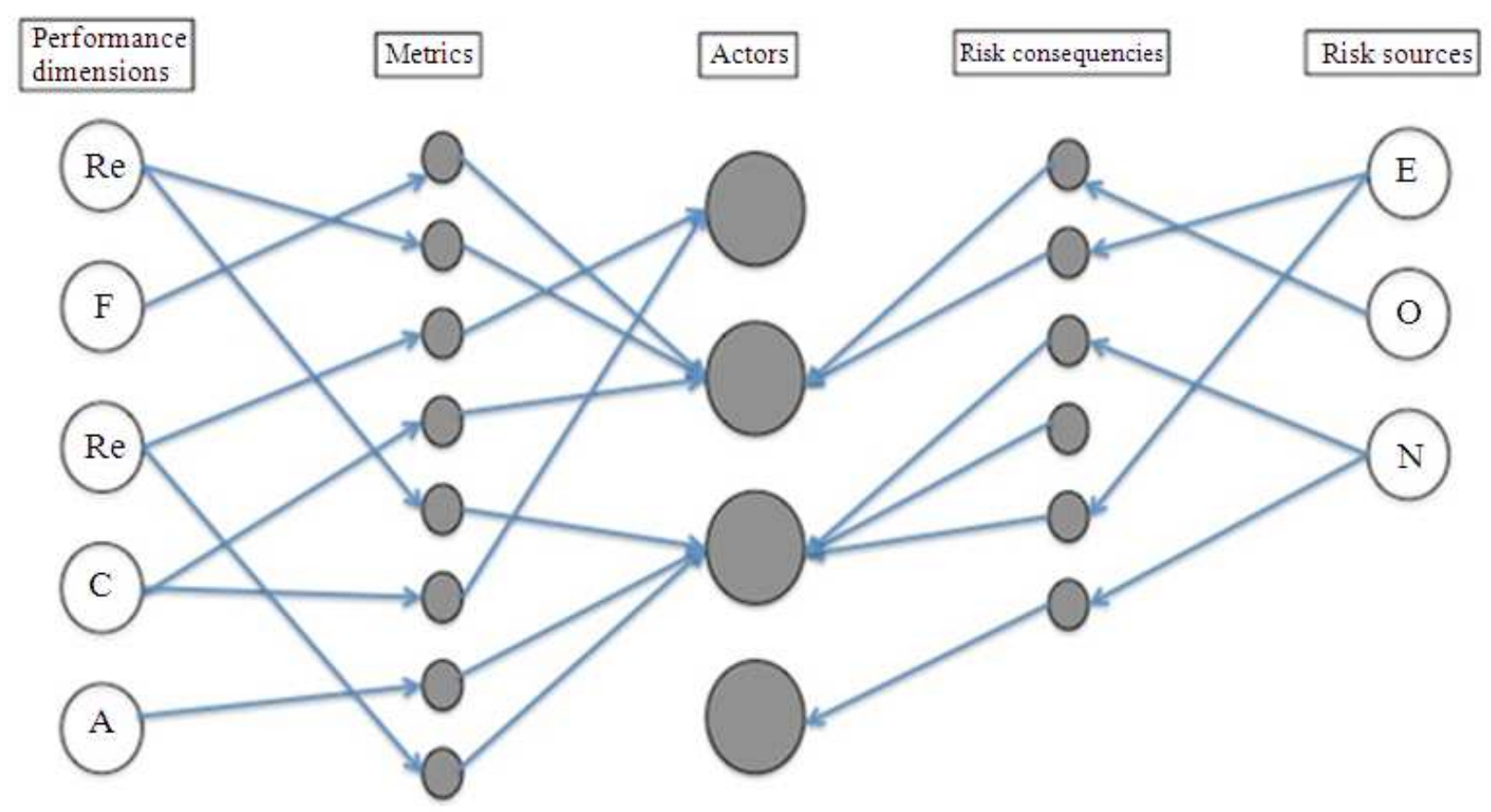

Fig. 6. Actors who are exposed to risk don't contribute to the performance

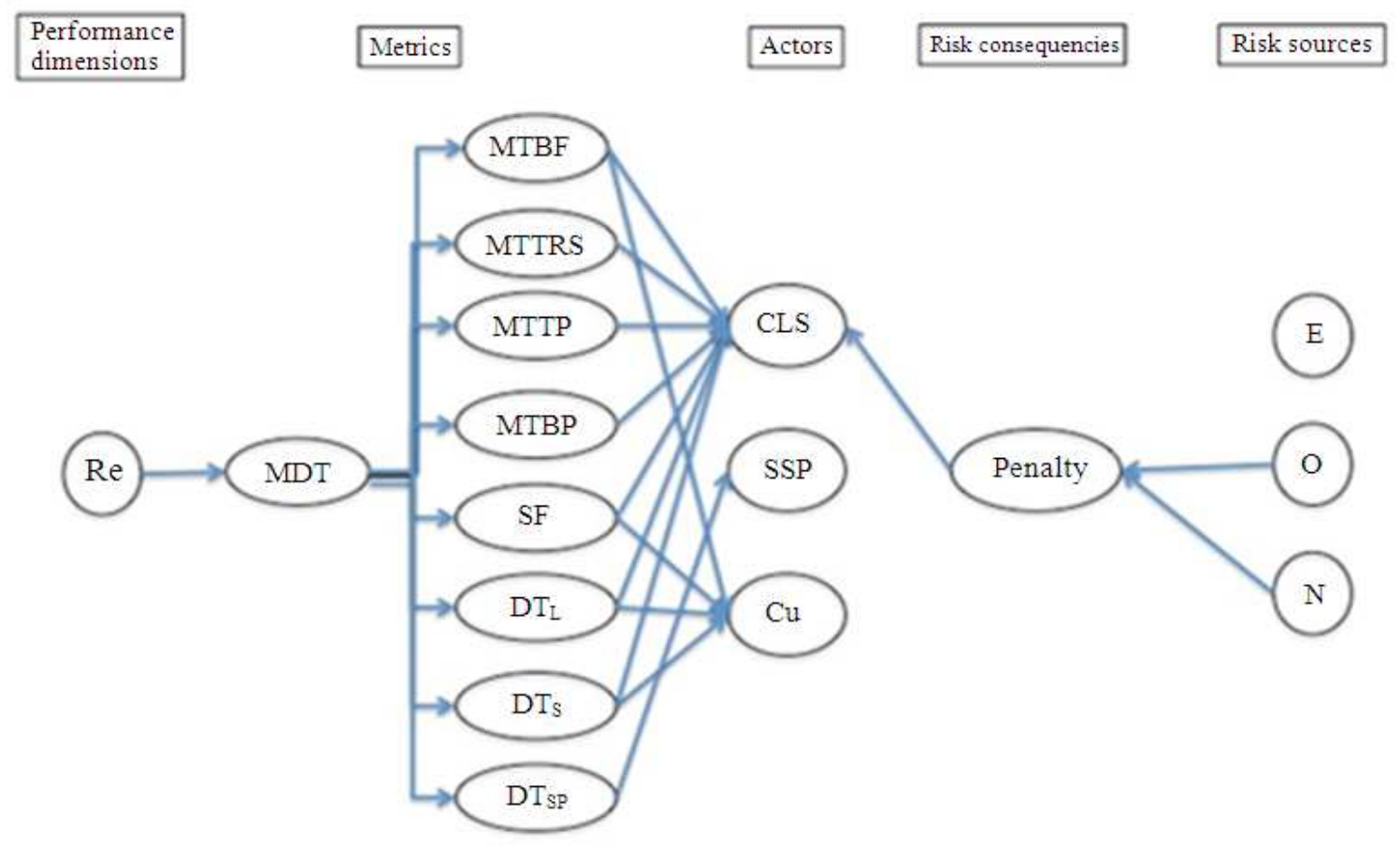

Fig. 7. The proposed framework for the ILS supply chain 


\subsection{Application and Results}

In this section we run a short application of the proposed model to the ILS-SC context. We limit the application just to the Responsiveness factor. The metric is the Mean Down Time, that is the average time that a system is non-operational.

According to the references Army Regulation 700127, 2012 (Nenni, 2013a; 2013b), Mean Down Time is:

$$
\begin{gathered}
\frac{\mathrm{SF} . \mathrm{MTTRS}+\left(\mathrm{DT}_{\mathrm{L}}+\mathrm{DT}_{\mathrm{S}}+\mathrm{DT}_{\mathrm{SP}}\right)}{\mathrm{MTBF}}+\frac{\mathrm{MTTP}}{\mathrm{MTBP}} \\
\frac{\frac{1}{\mathrm{MTBF}}+\frac{1}{\mathrm{MTBP}}}{\mathrm{MD}}
\end{gathered}
$$

Where:

MTBF $=$ The Mean Time Between Failures

MTTRS $=$ The Mean Time To Restore Systems

MTTP $=$ The Mean Time To Preventive

MTBP $=$ The Mean Time Between Preventive

Moreover SF is a skill factor, decreasing down to the asymptotic value of 1 as experience, training and expertise possessed by ILS staff grow. The SF has impact on the time to restore the system. The Delay Time is introduced for analyzing specifically the reason because an activity could be delayed. It is split up in Logistic Delay Time $\left(\mathrm{DT}_{\mathrm{L}}\right)$, in Staff Delay Time $\left(\mathrm{DT}_{\mathrm{S}}\right)$ and in Spare parts Delay Time $\left(\mathrm{DT}_{\mathrm{Sp}}\right)$. Each of these parameters is a driver to link the performance to the supply chain actors.

On the other hand the main risk for ILS contractor is to not meet the Service Level required by the Customer (low Operational Availability). The impact of this risk is a penalty paid by the CLS. All these elements are useful to design the framework of an ILS-SC, as in the Fig. 7.

In the ILS-SC major consequences as a penalty are paid by the CLS in case of poor performance (low Operational Availability of the system), but indeed the contribution on the performance is high even by SPP and Customer too. Reading trough the framework, we can see that we are in the first case of unbalanced framework, in which the most part of risks impacts on just an actor.

\section{CONCLUSION}

In this study we have proposed a framework to link performance, risk and SC actors. The aim is to put in evidence the unbalanced risk in order to solve it and improve thus the cooperation and integration along the supply chain. We have developed the framework just at qualitative level. The next step should be to improve the framework by using a tool, as ANOVA, to weight contribution from actor on metrics and to measure the impact of risks.

\section{REFERENCES}

Boon-itt, S. and C. Pongpanarat, 2011. Measuring service supply chain management processes: The application of the Q-sort technique. Int. J. Innov. Manage. Technol., 2: 217-221. DOI: 10.7763/IJIMT.2011.V2.134

Broekhuis, M., C.D. Blok and B. Meijboom, 2009. Improving client-centred care and services: The role of front/back-office configurations. J. Adv. Nurs., 65: $\quad 971-980 . \quad$ DOI: $\quad 10.1111 / \mathrm{j} .1365-$ 2648.2009.05014.x

Estampe, D., S. Lamouri, J.L. Paris and D.S. Brahim. 2013. A framework for analysing supply chain performance evaluation models. Int. J. Product. Econ., 142: 247-258. DOI: 10.1016/j.ijpe.2010.11.024

Juttner, U., H. Peck and M. Christopher, 2003. Supply chain risk management: Outlining an agenda for future research. Int. J. Logist. Res. Appli., 6: 197210. DOI: $10.1080 / 13675560310001627016$

Miller, K.D., 1992. A framework for integrated risk management in international business. J. Int. Bus. Stud., 23 : 311-331. 10.1057/palgrave.jibs. 8490270

Narasimhan, R. and T. Schoenherr, 2012. The effects of integrated supply management practices and environmental management practices on relative competitive quality advantage. Int. J. Product. Res., 50: $1185-1201$ DOI: $10.1080 / 00207543.2011 .555785$

Nenni, M.E., 2013a. Cost assessment for Integrated Logistic Support (ILS) activities. Int. J. Indus. Eng.

Nenni, M.E., 2013b. A cost model for integrated logistic support activities. Adv. Operat. Res., 2013: 127497. DOI: $10.1155 / 2013 / 127497$

Oehmen, J., A. Ziegenbein, R. Alard and P. Schönsleben. 2009. System-oriented supply chain risk management. Product. Plann. Control, 20: 343-361. DOI: $10.1080 / 09537280902843789$

Pache, G. and A. Spalanzani, 2007. La Gestion Des Chaînes Logistiques Multi-Acteurs: Perspectives Stratégiques. Presses universitaires de Grenoble, ISBN-10: 2706113804, pp: 256. 
PMI, 2013. A Guide to the Project Management Body of Knowledge. 5th Edn., Project Management Institute, Newtown, ISBN-10: 1935589679, pp: 589.

Ritchie, R.L., C.S. Brindley and N. Armstrong, 2008. Risk assessment and relationship management: Practical approach to supply chain risk management. Int. J. Agile Syst. Manage., 3: 228-247.

Saccani, N., P. Johannson and M. Perona. 2007. Configuring the after-sales service supply chain: A multiple case study. Int. J. Product. Econ., 110: 5269. DOI: $10.1016 /$ j.ijpe.2007.02.009

Singh, P.J., 2009. Improving Lead Times Through Collaboration with Supply Chain Partners: Evidence from Australian Manufacturing Firms. In: Rapid Modelling for Increasing Competitiveness: Tools and Mindset, Reiner, G. (Ed.). Springer, Dordrecht, ISBN-10: 1848827482, pp: 293-305.

Teng, B.S. and T.K. Das, 2008. Governance structure choice in strategic alliances: The roles of alliance objectives, alliance management experience and international partners. Manage. Decision, 46: 725742. DOI: $10.1108 / 00251740810873482$
Wagner, S.M. and C. Bode, 2008. An empirical examination of supply chain performance along several dimensions of risk. J. Bus. Logist., 29: $307-$ 325. DOI: 10.1002/j.2158-1592.2008.tb00081.x

Waters, D., 2011. Supply chain Risk Management: Vulnerability and Resilience in Logistics. 2nd Edn., Kogan Page Publishers, London, ISBN-10: 0749464267, pp: 264.

Zhen, W., 2011. The effect on inventory quantity by warehouse centralization. Proceedings of the 2nd IEEE International Conference on Emergency Management and Management Sciences, Aug. 8-10, IEEE Xplore Press, Beijing, pp: 136-138. DOI: 10.1109/ICEMMS.2011.6015638.

Zhou, H., W.C. Benton, D.A. Schilling and G.W. Milligan, 2011. Supply chain integration and the SCOR model. J. Bus. Logist., 32: 332-344. DOI: 10.1111/j.0000-0000.2011.01029.x 